\title{
FEATURE \\ Revisión histórica y científica sobre el desarrollo de la ganadería de leche en Puerto Rico con énfasis en el ganado pelón ${ }^{1,2}$
}

\author{
Héctor L. Sánchez-Rodríguez ${ }^{3}$
}

J. Agric. Univ. P.R. 103 (1):107-139 (2019)

\begin{abstract}
RESUMEN
Antes de la llegada de los conquistadores españoles, en el Nuevo Mundo no existían los bovinos domésticos. No fue hasta el 1493 que se introdujo por primera vez ganado proveniente de España a este territorio. Tras su adaptación y subsecuente reproducción mayormente por selección natural durante varios siglos, de este ganado ibérico se desarrolló nuestro ganado Criollo. Estos animales, de pequeño tamaño corporal, pelaje corto y alta adaptabilidad al trópico, formaron la base de nuestra ganadería durante cuatro siglos de gobierno español y durante los primeros 50 años de soberanía estadounidense. Durante este tiempo, el ganado Criollo aportó de modo notable al sustento, economía, cultura y política de nuestro pueblo. Principalmente a partir de la década del 1950, a través de programas de inseminación y de importación de ganado vivo, se introdujo a Puerto Rico (PR) genética mejorada para la producción de leche (i.e., Holstein), teniendo como base a nuestras vacas Criollas. Tras décadas de cruzamientos absorbentes, se ha alcanzado el fenotipo de las razas europeas mejoradas, pero manteniendo ciertas características de adaptación al medio ambiente tropical en una porción del ganado. Entre estas características se destacan un pelaje corto y una capacidad termorreguladora superior, las cuales no se encuentran en el ganado Bos taurus de clima templado. En esta revisión se pretende unir la evidencia histórica sobre el desarrollo de nuestra ganadería con la información científica reciente asociada al progreso de esta empresa y el alto grado de adaptación que nuestros animales han alcanzado ante las condiciones ambientales imperantes.
\end{abstract}

Palabras clave: historia de la ganadería puertorriqueña, vaca pelona, adaptación al trópico

\section{ABSTRACT}

Historical and scientific review of the development of dairy cattle in Puerto Rico with emphasis on short hair cattle

Before the Spanish conquest, there were no domestic bovines in the New World. In 1493, cattle from Spain were introduced for the first time in

${ }^{1}$ Manuscrito sometido a la Junta Editorial el 27 de abril de 2018.

${ }^{2}$ El autor desea agradecer a la Dra. Katherine Domenech y el Dr. Paul Randel por muy amablemente haber editado inicialmente este manuscrito.

${ }^{3}$ Catedrático Asociado, Departamento de Ciencia Animal, Universidad de Puerto Rico, Recinto de Mayagüez. 


\begin{abstract}
America. After several centuries of adaptation, our Criollo cattle evolved mostly by natural selection. These small-bodied, short-haired animals, highly adapted to the tropics formed the basis of our cattle industry during the Spanish colonial rule of Puerto Rico and during the first 50 years under the United States of America. The Criollo cattle contributed to the sustenance, economy, culture and politics of our country. Breeds selected for milk production (i.e., Holstein) were subsequently introduced to Puerto Rico, especially during the 1950 s, through insemination programs and cattle importations. This introduction of improved genetics in many cases was imposed on and fused with the existing Criollo cow. After decades of absorption crossing, an improved European breed phenotype has been achieved, while certain characteristics of adaption to a tropical environment have been maintained in a portion of our cattle. These features include a slick hair coat and a superior thermoregulatory capacity, which are not found in temperate climate Bos taurus cattle. This literature review seeks to combine the historic evidence of the development of our dairy cattle industry with recent scientific information about the adaptability of these animals.
\end{abstract}

Key words: Puerto Rican cattle industry history, slick- haired cow, adaptation to the tropics

\title{
INTRODUCCIÓN
}

Los aspectos del desarrollo histórico de la ganadería en Puerto Rico (PR) aparecen incompletos en las revisiones históricas disponibles, lo que probablemente se debe a que las recopilaciones hechas sobre este tema, sobre todo en sus inicios, se encuentran dispersas y en ocasiones carecen de detalles específicos. Con frecuencia esta información se encuentra en libros de historia que contienen solo párrafos u oraciones aisladas al respecto y, en casos menos frecuentes, relatos de varias páginas sobre nuestra ganadería en tiempos de dominio español. En cambio, existen diversas publicaciones muy completas referentes a la historia de nuestra ganadería en el periodo cercano al cambio en soberanía (principio siglo 20), pero probablemente por su antigüedad, estas publicaciones son de limitada disponibilidad. Aún más, sorprendentemente no fue posible encontrar escritos completos sobre la ganadería reciente en nuestro país. Por esto, y luego de varios años de búsqueda de literatura, el presente escrito compila los diferentes "pedazos" de esta historia que, lejos de ser definitiva, se presenta como la base para revisiones futuras con mayor detalle.

Nuestra ganadería ha sido parte esencial de la formación del pueblo puertorriqueño. Desde sus comienzos, la misma ha aportado al sustento, a la economía, a la cultura y a la política de nuestro pueblo. Este escrito comienza discutiendo los acontecimientos principales asociados con el desarrollo de nuestra ganadería desde que se introdujo el primer ganado al Nuevo Mundo desde España. Aquel ganado original se convirtió en nuestro ganado Criollo como resultado de un largo proceso de 
selección natural principalmente. Más tarde la raza Criolla se transformó en nuestro actual ganado con alta influencia de razas europeas, pero que todavía conserva en una porción de los animales diversas características de adaptabilidad a nuestro clima sumamente valiosas para la agricultura tropical moderna.

En este sentir, la presente revisión hace hincapié en el desarrollo de nuestro ganado lechero de pelo corto o "pelón", como localmente se conoce. Durante los últimos años, en PR ha surgido un interés genuino por parte de diferentes sectores de la industria lechera hacia el ganado adaptado a nuestras condiciones ambientales, animales que en el pasado han sido quizás menospreciados en nuestra agricultura. Esta revisión se concentra en describir la procedencia y desempeño de tales animales basado en la evidencia histórica disponible al momento y también en los hallazgos científicos recientes en los casos que así lo ameritan. Además, la discusión se fortalece en ocasiones mediante alusión a resultados científicos procedentes de otros escenarios en el mundo.

\section{DISCUSIÓN}

\section{Ganadería En Puerto Rico Bajo El Régimen De España (1493-1898)}

\section{Llegada del ganado bovino a Puerto Rico}

Antes del proceso de colonización europea, en el Nuevo Mundo no existían bovinos domésticos (Picó, 2008). La primera entrada de estos animales al territorio americano ocurrió como parte del segundo viaje de Cristobal Colón (19 de noviembre de 1493), cuando se introdujo ganado vacuno a la isla de La Española, la que hoy día ocupan la República Dominicana y Haití (Rouse, 1977; Primo, 1992; Rodero et al., 1992; Brau, 2011; Martínez et al., 2012). En el caso de PR, la primera introducción de bovinos domésticos documentada ocurrió en el 1505 por parte de Vicente Yañez Pinzón (Rouse, 1977). Aunque las razones no están claras en la literatura, se entiende que esta introducción se vio afectada por problemas con la embarcación que transportaba estos animales, resultando en que los mismos fueran liberados y escaparan a las montañas de la Isla (Rouse, 1977). Allí se reprodujeron entre sí, aportando luego su genética a las introducciones posteriores de ganado (Rouse, 1977).

Es importante tener presente que La Española jugó un papel clave en las primeras décadas de la colonización hispana y de allí salió una parte considerable del ganado destinado a la colonización de nuevos territorios americanos, inicialmente incluyendo a PR (Rouse, 1977). De 
hecho, para el 1509-1510 Juan Ponce de León introdujo más ganado vacuno a PR procedente de La Española (Rouse, 1977; Molina, 2001; Brau, 2011). Sin embargo, para asegurar abastos adecuados de comida para los pobladores de La Española, inicialmente el gobierno español limitó la exportación de ganado desde dicha Isla caribeña (Rouse, 1977). Por consiguiente, no fue hasta el 1511 que don Luis Fernando de Alfaro obtuvo la primera licencia o permiso por parte del rey de España, Fernando el Católico, e introdujo su ganado vacuno a PR procedente del vecino país (Rouse, 1977; Molina, 2001; Ramírez, 2007; Brau, 2011).

Además de estas introducciones de ganado, entre los años 1511-1513 llegó también a PR un barco con ganado proveniente directamente de España, aunque no se especifica de qué especies de animales se trataba (Brau, 2011). Según este autor, entre el 1516-1518 los religiosos, como partícipes de la colonización, recomendaron aumentar la crianza de ganado en PR y así también entre 1516-1519 Fernando de Aragón promovió el aumento en la cantidad de ganado presente en nuestra Isla. Estas introducciones de ganado desde España directamente a PR continuaron hasta el 1512, cuando ya la Española tenía suficiente ganado como para exportar a las demás Antillas, incluyendo a nuestra Isla (Rouse, 1977). Según Rouse (1977), en el 1541 hubo una introducción a PR de vacas y toros "seleccionados" provenientes directamente de España. A raíz de todas estas introducciones, los bovinos ibéricos primeros del Nuevo Mundo, incluyendo a PR, constituyeron una sólida base para el desarrollo del ganado local.

Una vez establecido como país ganadero, PR se convirtió en una fuente importante de animales al continuar la conquista de nuevos territorios en el Nuevo Mundo (Rouse, 1977). De acuerdo con Cestero (1947) desde 1877 hasta 1905, PR exportó gran cantidad de ganado. Posteriormente, la ganadería se redujo, limitando así las exportaciones porque la industria azucarera acaparó gran parte de los terrenos agrícolas de la Isla (Cestero, 1947). Todos estos eventos históricos dieron origen a la ganadería en PR.

\section{Procedencia del ganado que llegó al Nuevo Mundo}

Puesto que los barcos de los colonizadores zarpaban de España, se entiende que la gran mayoría del ganado traído al Nuevo Mundo provenía de dicha nación (Rodero et al., 1992). También, es un hecho importante que dichos barcos acostumbraban hacer parada para reabastecerse en las Islas Canarias, donde también, según evidencia histórica, se adquiría ganado para llevarlo al Nuevo Mundo (Rodero et al., 1992; Brau, 2011). Sin embargo, fue solo unos 20 años antes de la conquista del Nuevo Mundo que España colonizó a las Islas Canarias, donde no habían vacunos en un principio, por lo que se entiende que el ganado 
canario también se originó en España (Rouse, 1977). Además, más antiguamente a España llegó ganado proveniente de África (Bracho et al., 2002) y durante la colonización los viajes desde África al Nuevo Mundo fueron comunes debido a la trata de esclavos. Por estas razones se cree que al Nuevo Mundo también se introdujeron indirecta (Bracho et al., 2002) y/o directamente animales de ese continente (Rouse, 1977).

Aunque la literatura no especifica cuales razas de bovinos domésticos fueron traídas inicialmente al Nuevo Mundo, varios investigadores historiadores creen que se trató de las razas ibéricas comunes en aquella época, entre ellas, el Retinto, Asturiano, Berrenda en Colorado y Rubia Gallega (Rodero et al., 1992; Ortiz, 1997), así como el Andaluz y el Cacereño (Rouse, 1977).

\section{Desarrollo del ganado Criollo del Nuevo Mundo}

Contrario a la práctica moderna, el ganado inicialmente introducido al Nuevo Mundo, incluyendo a PR, fue liberado en las respectivas islas (McTavish et al., 2013). Ante la ausencia de enfermedades y expuestos a un clima tropical benigno, el ganado liberado se multiplicó rápidamente (Sponenberg y Olson, 1992; Picó, 2008). De hecho, la eficiencia reproductiva de estos animales fue tal que en PR dio origen a lo que conocemos como los grandes hatos, los cuales eran grandes extensiones de terreno dedicadas a la cría de ganado libre perteneciente a diferentes dueños (Picó, 2008; Scarano, 2008). Estos hatos fueron de tal importancia histórica que todavía hoy día varios pueblos y barrios de nuestra isla conservan sus nombres, incluyendo a Hatillo, Hato Rey, Hato Tejas, Hato Grande, Hato Arriba, Hato Abajo, Hato Nuevo y Hato Viejo (Scarano, 2008).

Tras siglos de selección genética, principalmente de índole natural, en los aludidos hatos, el ganado introducido por los colonizadores se convirtió en el ganado Criollo de PR y de otras partes del Nuevo Mundo (Rouse, 1977; McTavish et al., 2013). Este ganado resultó ser altamente adaptado a las condiciones ambientales tropicales en diversos países americanos (Cestero, 1947; Bethancourt y Toribio, 2013; Huson et al., 2014), siendo inicialmente utilizados para múltiples propósitos, incluyendo trabajo, carne y leche (Gaztambide, 1974; Wilson, 2009).

Físicamente, el ganado Criollo de la parte tropical de Iberoamérica es de un tamaño corporal pequeño; el color de su pelaje es una gradación del marrón (variando desde crema hasta rojizo), a veces con una sombra negra parecida a la observada en algunos ejemplares de la raza Jersey, aunque puede también presentar manchas blancas de pequeño tamaño (Bethancourt y Toribio, 2013). El pelaje es sumamente corto en todo el cuerpo y en algunas ocasiones puede lucir brilloso (Bethancourt y Toribio, 2013). Aunque una porción considerable del ganado Criollo 
posee cuernos de tamaño prominente, existen animales acornes, como se observa en el ganado Romosinuano de Colombia (Rouse, 1977). Probablemente la notable presencia de cuernos en gran parte del ganado Criollo se debe a que uno de los propósitos originales de estos animales fue para el trabajo (Cestero, 1947; MacPhail, 1963), por lo que era necesario atar el yugo a sus cuernos. Entre las fotos más antiguas (con buena resolución) disponibles sobre nuestra vaca Criolla, se destacan dos: una tomada por Jack Delano en 1941, que ahora forma parte del archivo de la Biblioteca del Congreso (http://www.loc.gov/pictures/item/ fsa1998009948/PP/), y la otra se encuentra en el archivo de fotos tomadas por fotógrafos del periódico El Mundo y que ahora pertenecen a la Biblioteca Digital Puertorriqueña de la Universidad de Puerto Rico en Río Piedras (tomada el 25 de julio de 1948 en Barceloneta; http:// bibliotecadigital.uprrp.edu/cdm/ref/collection/ELM4068/id/1111). Además, existen otras fotos pertinentes de bueyes Criollos de la industria azucarera tomadas por Jack Delano durante los años ' 40 en PR, las cuales aparecen en el archivo de la Biblioteca del Congreso (http:// www.loc.gov/pictures/item/fsa1998010472/PP/; http://www.loc.gov/pictures/item/fsa2000029070/PP/). También, hay fotos similares recopiladas en el libro titulado Puerto Rico Mío (Delano, 1990) del Instituto Smithsonian. En todas estas imágenes se observan las características físicas aludidas.

En su libro, Rouse (1977) menciona que aunque existe la posibilidad de que otras potencias europeas de la época, como Francia, introdujeran también su ganado a sus colonias en el Nuevo Mundo, estas introducciones fueron insignificantes en comparación con el ganado de origen español. De hecho, si comparamos físicamente el ganado Criollo de todos los países que fueron antiguas colonias de España en el Nuevo Mundo de ambiente tropical, se observa gran similitud entre sí (Rouse, 1977). Se prestan para propósitos de comparación visual las fotos previamente publicadas por otros investigadores que ilustran el Criollo Limonero de Venezuela (Contreras et al., 2012), el Criollo Lechero de República Dominicana (García et al., 2015), el Criollo Lechero de México (Canales, 2014) y el Hartón del Valle en Colombia (Barrera et al., 2006), entre otros.

\section{Economía asociada a los comienzos de la ganadería en Puerto Rico}

Mientras PR perteneció a España su ganado Criollo fue utilizado mayormente para subsistencia, supliendo la carne y leche necesarias para la población, incluyendo a la guarnición de San Juan durante el siglo XVIII (Scarano, 2008). En aquella época la producción agrícola ubicada alrededor de los centros urbanos se encargaba de suplir co- 
mida a los residentes españoles (Scarano, 2008). Durante este tiempo, y gracias a su excelente reproducción, nuestro ganado también fue exportado hacia los nuevos territorios que España iba colonizando en América (Molina, 2001; Scarano, 2008).

La piel de vaca era sumamente codiciada en Europa, por lo que la exportación de cueros pasó a ser una de las primeras actividades económicas importantes de nuestra Isla (Rouse, 1977; Picó, 2008; Scarano, 2008; Brau, 2011). Tanto fue así que los cueros no se prestaban solamente para el comercio legal con España, sino que también fueron de suma importancia en el contrabando con otras potencias de Europa, cuyos mercantes llegaban hasta nuestras costas (Picó, 2008; Scarano, 2008). La demanda por la piel de las reses, que andaban libres en los hatos, era tal que se cazaban como animales salvajes por su piel únicamente; descartándose la canal, cuya carne fue parte importante en la dieta de los esclavos cimarrones, quienes habían escapado de sus amos y vivían fugitivos en los montes de la Isla (Scarano, 2008).

\section{Implicación de la ganadería en el desarrollo de la propiedad privada en Puerto Rico}

La existencia de los grandes hatos en PR fue posible debido a que inicialmente el recurso tierra pertenecía al Rey de España o a sus representantes, por lo que los residentes de la Isla pudieron hacer uso común de grandes extensiones de terreno sin poseer un título de propiedad, sobre todo desde principios del siglo XVI (Scarano, 2008). A la misma vez se desarrollaron en la isla las estancias, pedazos de terreno dedicados a los cultivos y ubicados entre los hatos (Scarano, 2008). Lógicamente, esta situación se prestó para causar conflictos entre las diferentes partes interesadas en el uso del terreno.

Ya para el 1541 comenzaron una serie de disputas entre los usuarios de los hatos por el poder en relación a estos terrenos (Scarano, 2008). A partir del 1720 los altercados entre los dueños del ganado en los hatos y los dueños de los cultivos en las estancias también se fueron incrementando por el uso de este recurso (Picó, 2008; Scarano, 2008). Tanto ascendieron estos conflictos entre los residentes de la colonia, que para el 1757 el gobierno español creó la Reforma Agraria y con la Real Cédula de 1778 se eliminaron los grandes hatos y se comenzó la repartición de títulos de propiedad sobre las tierras. En términos de jurisprudencia, este cambio dio comienzo a la propiedad privada en nuestra isla (Picó, 2008; Scarano, 2008; Cosme, 2009).

Históricamente esta Reforma Agraria obedeció a que España quería desarrollar en PR una "agricultura comercial de exportación" (Picó, 2008). Sin embargo, nuestra ganadería ejerció un rol importante en estos procesos por los posibles daños que causara el ganado a los cul- 
tivos en las estancias, así como por la necesidad de cercar dichas plantaciones para protegerlas. Los problemas entre hateros y estancieros forzaron al gobierno español a tomar acción al respecto.

\section{Ganadería En Puerto Rico Bajo Estados Unidos de América (1898-presente)}

\section{Ganadería de Leche en Puerto Rico antes del 1950}

Como resultado del Tratado de Paris, el cual puso fin a la guerra hispanoamericana de 1898, ocurrió el cambio de soberanía cuando PR se convirtió en territorio de Estados Unidos de América (EEUU; Cestero, 1947; Scarano, 2008). Al realizarse un censo pecuario un año después, en el 1899, PR contaba con una población de sobre 260,000 cabezas de vacunos Criollos (Rouse, 1977). Durante los primeros 50 años de soberanía norteamericana la ganadería de leche de PR tuvo un desarrollo sumamente lento (Ramírez, 2007), siendo la producción de leche y de carne complementaria a la crianza de bueyes para trabajar en la industria azucarera (MacPhail, 1963). Durante esta época, la Isla contaba principalmente con el ganado Criollo y aunque sí hubo importación de ganado de razas europeas seleccionadas para producir leche, estas no tuvieron un impacto genético importante debido a su limitada cantidad (Cestero, 1947; Jones, 1951; MacPhail, 1963; Rouse, 1977; Molina, 2001). Hacia finales de la década del 1940, PR contaba con unas 315,835 cabezas de bovinos (Cestero, 1947).

El ganado Criollo hispanoamericano está bien adaptado a las condiciones ambientales tropicales, pero sus niveles de producción son muy inferiores a los observados en razas lecheras en países de clima templado (Bracho et al., 2002; Isea-Villasmil y Aranguren-Méndez, 2005). Por esto, en PR se recurrió a la importación de razas lecheras mejoradas con la intención de aumentar el desempeño productivo. El mismo año del cambio en soberanía (1898), de EEUU se importaron ejemplares de las razas Jersey, Guernsey, Holstein y Ayrshire, pero el número de animales involucrados fue sumamente limitado (Cestero, 1947). Luego, alrededor de 1910 continuaron las importaciones a PR de diversas razas europeas de tipo lechero, incluyendo la Holstein Friesian, Milking Shorthorn, Jersey, Guernsey, Pardo Suizo y Ayrshire (Cestero, 1947; MacPhail, 1963; Molina, 2001). Según Gaztambide y Arán (1941) las vacas locales fueron cruzadas con "ganado americano" importado con el propósito de incrementar la producción de leche en su progenie. También, para el año 1947, Cestero reportó que el hato del Colegio de Agricultura y Artes Mecánicas tenía ganado Guernsey disponible para la venta a los ganaderos del país. En la página 20 del libro de Gaztambide (1974) se observa una foto del ganado Guernsey del Colegio de Cien- 
cias Agrícolas. Además, la Compañía Agrícola de Puerto Rico (PRACO, por sus siglas en inglés) había importado ganado Pardo Suizo y Jersey para establecer dos hatos en la Isla de Vieques con el propósito de evaluar su desempeño y luego vender la progenie a los ganaderos del PR (Cestero, 1947).

Sin embargo, estas tempranas introducciones debieron estar limitadas a un pequeño sector pudiente del país, mientras para la mayoría de la gente imperaba una precaria situación económica durante esa época (Scarano, 2008). Atestiguan esta realidad las fotos tomadas por Jack Delano en PR durante la década de los '40 (Biblioteca del Congreso: http://www.loc.gov/pictures/item/fsa2000029509/PP/; http:// www.loc.gov/pictures/item/fsa2000029602/PP/; http://www.loc.gov/ pictures/item/fsa2000029753/PP/; http:/www.loc.gov/pictures/item/ fsa1998009876/PP/; http://www.loc.gov/pictures/item/fsa2000028215/ PP/; http://www.loc.gov/pictures/item/fsa2000029448/PP/) y aquellas publicadas por el Instituto Smithsonian en el libro titulado Puerto Rico Mío (Delano, 1990). A propósito, desde un punto de vista literario en su cuento El Josco, don Abelardo Díaz Alfaro (2011) logró plasmar detalladamente la desigualdad social y económica imperante entre los años 1930 - 1940 y la pobreza en que vivía sumida la mayor parte de la población de PR. En este cuento se relata la importación de un toro "americano" para ser usado como padrote en sustitución del toro Criollo por parte del dueño de una finca quien, además de tener ganado, también se dedicaba al cultivo de la caña de azúcar, lo que sugiere que era una persona pudiente. De hecho, antes de la década del 1950 la importación de toros pura sangre de EEUU fue muy limitada (Cestero, 1947). Adicionalmente, en el archivo histórico del periódico El Mundo, ahora propiedad de la Universidad de Puerto Rico, Recinto de Río Piedras, se pueden observar las fotos tomadas el 3 de diciembre de 1944 en la vaquería de Jesús T. Piñero en Carolina (http://bibliotecadigital. uprrp.edu/cdm/ref/collection/fotoselmund/id/1687; http://bibliotecadigital.uprrp.edu/cdm/ref/collection/fotoselmund/id/1688; http://bibliotecadigital.uprrp.edu/cdm/ref/collection/fotoselmund/id/1692). En los animales que aparecen en estas fotos se observa una alta influencia de razas europeas como la Holstein y la Jersey. Jesús T. Piñero fue el primer puertorriqueño en ser gobernador de PR, pero designado por el presidente de EEUU (Baldrich, 1999), quien estuvo involucrado en las industrias azucarera y lechera (Pyle et al., 2016). Esta evidencia fotográfica e histórica apoya la idea de que inicialmente las importaciones de ganado mejorado tuvieron un impacto considerable solo en un limitado sector del país con alto poder adquisitivo. Sin embargo, como se menciona anteriormente, para esta época el ganado de PR seguía siendo en su inmensa mayoría ganado Criollo de origen español (Rou- 
se, 1977). Este hecho se evidencia también en los bueyes usados para trabajar en la caña que se observan en las fotos tomadas por Jack Delano en la década del 1940, tanto en la Biblioteca del Congreso (http:// www.loc.gov/pictures/item/fsa1998010472/PP/; http://www.loc.gov/pictures/item/fsa2000029070/PP/), como en el libro titulado Puerto Rico Mío (Delano, 1990).

En su artículo, Kabumbuli y Phelan (2003), al igual que en la página de Internet titulada "The Seagoing Cowboys" (https://seagoingcowboysblog.wordpress.com/tag/puerto-rico/), se relata el rol que tuvo el programa "The Heifer Project" para promover la llegada de ganado lechero mejorado a PR durante los años '40. Se trata de una organización benéfica que intenta aliviar la pobreza y malnutrición en el mundo a través de préstamos de animales (Kabumbuli y Phelan, 2003). Según su modo de operar, al identificar una familia en necesidad, esta organización le donaba una novilla de raza mejorada con la condición de que la familia receptora donara a otra familia pobre la primera hija del animal donado (Kabumbuli y Phelan, 2003). En la década del 1940 esta entidad facilitó 18 novillas lecheras (de las razas Guernsey, Jersey y Milking Shorthorn) provenientes de EEUU a diferentes familias en PR (Kabumbuli y Phelan, 2003), contribuyendo así a las importaciones a nuestra isla.

Como dato pertinente, para el 1944 la compañía Roberto Colón Machinery introdujo a PR las primeras máquinas de ordeño de la marca Surge (Molina, 2001). En el archivo de fotos del periódico El Mundo tomadas en la vaquería de Jesús T. Piñero, también aparece un empleado de su vaquería trabajando con un equipo de ordeño mecánico durante ese mismo año (http://bibliotecadigital.uprrp.edu/cdm/ref/collection/ fotoselmund/id/1693), lo que conduce a la inferencia de que se trata de uno de los equipos antes mencionados. Esta observación también parece indicar que antes del 1950 los cambios considerables en la ganadería de PR estuvieron limitados principalmente a un pequeño grupo de gente con alto poder adquisitivo.

Como dato curioso, la colección de fotos de la Biblioteca del Congreso también incluye fotos de bueyes de caña con una evidente alta influencia Brahman (http://www.loc.gov/pictures/item/fsa2000029794/ PP/; http://www.loc.gov/pictures/item/fsa2000029782/PP/); estas fotos fueron tomadas en Arecibo en 1941 por Jack Delano. Según Cestero (1947), el Brahman fue introducido a PR proveniente de Texas con la idea de aumentar el tamaño y capacidad de trabajo de los bueyes Criollos. Esto nos sugiere que durante esta época la industria de ganado de carne tuvo una historia similar a la lechera. Otro hecho pertinente es que, según MacPhail (1963), contrario a la situación actual en que la inmensa mayoría de las vaquerías de leche de PR se encuentran en el 
área norte, para el año 1960 existían numerosas fincas lecheras en el área sur de PR. Dicho autor afirma que para enfrentar las condiciones ambientales cálidas y secas del sur de la isla era necesario seguir utilizando ganado Criollo, así como cruces de este o de Cebú con Holstein, contrario al área norte donde el ganado Holstein ya era mayoría en las vaquerías. Cestero (1947) había mencionado previamente que fue necesario mantener el ganado Criollo en el área sur de PR por su capacidad para utilizar forrajes de pobre calidad nutricional asociados con las condiciones ambientales del sur. Sin embargo, más tarde la mayoría de las vaquerías del área sur de PR desaparecieron (y las que aún quedan comúnmente usan animales completamente Bos taurus), por lo que podemos presumir que esta influencia Bos indicus es insignificante desde el punto de vista del ganado lechero actual. Por otra parte, estos animales importados podrían haber influenciado el ganado de carne de la región sur, donde hoy día la presencia cebuína es altamente evidente.

A pesar de todo lo antes expuesto, es notable que durante los primeros años del siglo 20 y antes de ser parcialmente sustituida por la industria azucarera, nuestra ganadería Criolla alcanzó tal cantidad de animales que desde PR se exportó ganado a la isla de Cuba (Gaztambide y Arán, 1941).

\section{Ganadería de Leche en Puerto Rico después del 1950}

A partir de la década del 1950 la ganadería en PR sufrió una serie de cambios sumamente significativos que dieron origen a la industria lechera, tal como la conocemos hoy día. Durante los años '40 en PR y en EEUU ocurrieron una serie de eventos históricos que dieron paso a la reconstrucción económica de nuestro país y que, directa o indirectamente, transformaron nuestra ganadería. Tal como relatan los libros de Picó (2008) y de Scarano (2008), estos acontecimientos históricos incluyeron: los programas de reconstrucción económica establecidos una vez finalizada la gran depresión del 1930-40, la culminación de la segunda guerra mundial (1939-45) y el hecho de que por primera vez PR tuviera un gobernador puertorriqueño y electo por el pueblo en el año 1948.

Estos grandes cambios conllevaron la implantación en PR de varios programas de reestructuración económica, los cuales permitieron el acceso de las masas, incluyendo la parte de la población de escasos recursos económicos, a adquirir animales con alta influencia de las razas de ganado mejoradas previamente mencionadas. De hecho, MacPhail (1963) y Rouse (1977) reportaron que después de la segunda guerra mundial la industrialización de PR cambió por completo la ganadería con la sustitución del ganado Criollo principalmente por la raza Holstein para fines lecheros y por la raza Brahman para la producción de 
carne. Según Gaztambide et al. (1952) y Gaztambide (1974), el ganado Criollo y el Brahman eran los más importantes en la industria de carne de PR en esa época, mientras el Hereford fue introducido en cantidades considerables posteriormente. Debido a que el ganado Criollo posee una alta adaptación al trópico, así como una alta fertilidad y longevidad, al ser utilizado como base en cruzamientos absorbentes con razas seleccionadas para un tipo en específico (en nuestro caso el lechero), este debió haber aportado cierta rusticidad en al menos una porción de la progenie (Gaztambide, 1974; Bracho et al., 2002).

Como una de las medidas para fomentar la ganadería de leche en la Isla, entre el 1952-1954 el gobierno de PR comenzó un programa de inseminación artificial y de monta natural con el propósito de promover el mejoramiento genético e incrementar la producción de leche en la Isla (MacPhail, 1963; Molina, 2001; Ramírez, 2007). Dicho programa de inseminación artificial, el cual tenía el propósito de proveer buenos sementales a precios accesibles (Gaztambide, 1974), fue creado en virtud de la ley número 38 del 27 de marzo de 1951 con miras a mejorar la capacidad productora de las vacas de los hatos lecheros de PR. Además del programa de inseminación artificial, el gobierno importó toros de alto mérito genético de razas lecheras como la Holstein, los cuales se pusieron al servicio de los ganaderos del país, quienes podían llevar sus vacas Criollas en celo para ser empadronadas (MacPhail, 1963). A propósito, en el archivo histórico del periódico El Mundo (Biblioteca Digital Puertorriqueña, Universidad de Puerto Rico, Recinto de Río Piedras) se halla un artículo titulado: "Traen semen por ruta aérea para programa de inseminación artificial en sur de la Isla. Más de 800 vacas apareadas en Coamo y Aibonito." Este artículo, publicado en el 1953, incluye la foto de una avioneta lanzando un paquete atado a un pequeño paracaídas sobre una finca de Aibonito, como modo de entregar semen proveniente del estado de Ohio para el programa de inseminación artificial que se llevaba a cabo en PR (http://bibliotecadigital.uprrp.edu/cdm/singleitem/collection/ELM4068/id/3310/rec/1). De hecho, en la página 49 del libro publicado con motivo del centenario de la "American Dairy Science Association" (Jones, 2006) se hace alusión a la "Northern Ohio Breeder's Association" la cual comenzó a distribuir semen de toro durante la década del 1940 por rutas aéreas. En esta se observa la foto de una avioneta y un paquete de semen atado a un paracaídas, sumamente similares a los que aparcen en el artículo del periódico El Mundo antes mencionado. MacPhail (1963) mencionó que para el año fiscal 1958-1959 un total de 12,300 vacas provenientes de 1,000 fincas fueron inseminadas artificialmente a raíz de este programa. También, en su libro, el Dr. Gaztambide (1974) presenta las fotos de varios de los toros utilizados por el centro de inseminación artificial 
de PR, incluyendo a Willards Molino Leader (página 18) y Bern-Bry Reflection Sovereign (página 35), así como de las facilidades del laboratorio de inseminación (página 122), uno de los técnicos inseminadores (página 71) y de una de las jaulas de colección de semen (página 71). En este libro también se hace mención del toro Wisconsin Astronaut, el cual fue comprado por el centro de inseminación artificial de PR por $\$ 5,000$. Para propiciar el uso de estos sementales mejorados se crearon también una serie de incentivos monetarios, por ejemplo, cada vez que nacía un becerro blanco y negro en su hato, el ganadero recibía un incentivo monetario (comunicación personal con Gilberto Sánchez, agricultor del pueblo de Yauco).

Además, ya tan temprano como el 1955 se estaba introduciendo a PR ganado mejorado procedente de EEUU y Canadá (Ramírez, 2007). Estas importaciones, principalmente de novillas, aunque con fluctuaciones considerables a través del tiempo, han continuado hasta el presente y en muchas ocasiones han sido incentivadas por el gobierno de PR. A modo de ejemplo, el Reglamento número 4442 del 3 de mayo de 1991 fue creado para regir el programa de incentivos para la importación de vacas lecheras. Este establece una ayuda económica de \$200 por cada novilla de reemplazo comprada e importada de EEUU a PR hasta el límite de un número de animales equivalente al $25 \%$ de las vacas en producción en el hato. Como resultado de estas prácticas, a través de los años ha llegado a la isla una cantidad considerable de ganado puro mejorado o de híbridos de estas razas provenientes mayormente de la parte sur de EEUU, pero en ocasiones también de los estados lecheros del norte y de Canadá.

También, y motivado por el mal estado nutricional de una gran parte de la población puertorriqueña, para el año 1953 el gobierno de PR inició varios programas para distribuir leche a la juventud (incluyendo los comedores escolares), lo cual incentivó aún más el crecimiento de nuestra industria lechera (MacPhail, 1963). Además, en 1957 comenzó un programa para hacer accesible a familias de bajos recursos económicos animales mejorados para producción de leche a traspatio (MacPhail, 1963). Esto se evidencia en una foto del Periódico El Mundo (en el archivo de la Biblioteca Digital Puertorriqueña de la Universidad de Puerto Rico, Recinto de Río Piedras) que data de esa época (http://bibliotecadigital.uprrp.edu/cdm/ref/collection/fotoselmund/id/646). Otro factor pertinente fue la reestructuración económica de PR que resultó en un aumento en la población de las ciudades, así como en el ingreso per cápita del pueblo, lo que incentivó la demanda por leche entre los años 1940-1960, a beneficio de la creciente industria lechera (MacPhail, 1963). También, para el año 1956 se estableció la Oficina para la Reglamentación de la Industria Lechera (Ramírez, 2007) bajo la ley 
106, luego enmendada a la ley 34 de 1957, la cual sigue vigente hasta el día de hoy.

De esta manera, a través de cruzamientos absorbentes e importaciones de ganado lechero principalmente de EEUU, la población original de vacas totalmente Criolla de PR se transformó en la actual población compuesta primordialmente por animales de la raza Holstein. La Figura 1 ilustra cómo a partir de cinco generaciones consecutivas de cruzamientos absorbentes usando sementales Holstein puros, se convierte la hembra $100 \%$ Criolla en una descendiente de composición racial

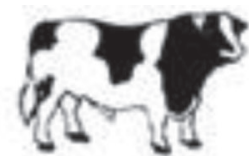

Holstein 1

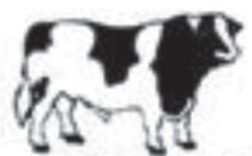

Holstein 2

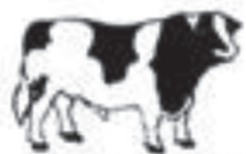

Holstein 3

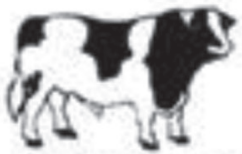

Holstein $\widehat{\alpha} 4$

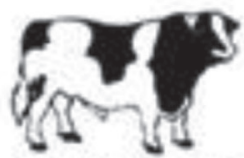

Holstein $\delta 5$
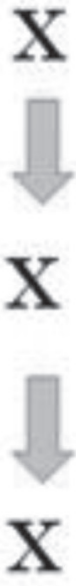

$\mathrm{X}$
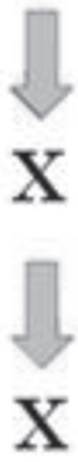

F3 $9=\mathbf{8 7 . 5} \%$ Holstein : $\mathbf{1 2 . 5} \%$ Criolla

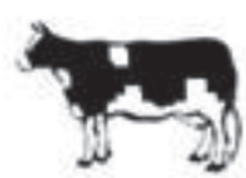

F1 $=\mathbf{5 0} \%$ Holstein : $\mathbf{5 0} \%$ Criolla

F2 $=75 \%$ Holstein : $25 \%$ Criolla

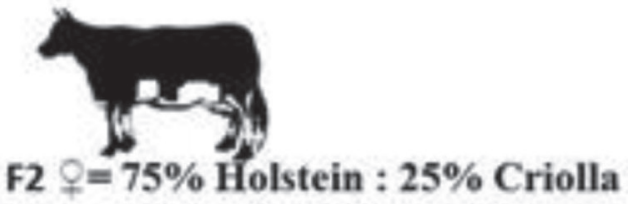

Criolla $\stackrel{\circ}{+}$
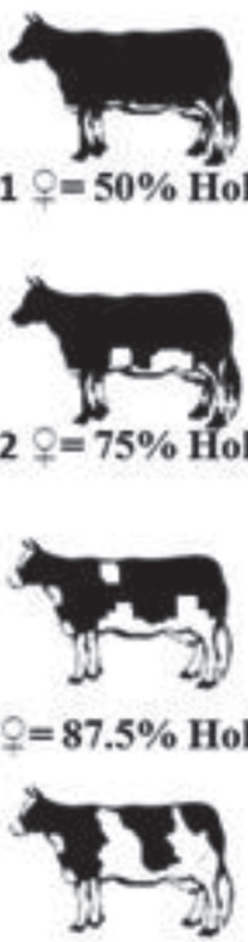

F4 $q=93.75 \%$ Holstein : $6.25 \%$ Criolla

FiguRA 1. Esquema representativo del programa de cruzamientos absorbentes llevado a cabo en Puerto Rico de manera intensiva a partir de la década del 1950. 
93.75\% Holstein y tan solo $6.25 \%$ Criolla (o expresada de otra manera, 15/16 Holstein y 1/16 Criolla). Este proceso, aunque comenzó antes, se ha ido llevando a cabo en PR intensamente desde la década del 1950. Incluso, en el archivo del periódico El Mundo (año no determinado) se puede observar la foto de un ganadero de Aguadilla quien se ganó una vaca recién parida con alta influencia Holstein como parte de un sorteo auspiciado por el Departamento de Agricultura y Comercio (http:// bibliotecadigital.uprrp.edu/cdm/ref/collection/fotoselmund/id/646). La vaca en la foto presenta características físicas intermedias entre las razas Holstein y Criollo. A saber, su pelaje es predominantemente de color blanco (característica de la raza Holstein), pero su tamaño corporal es pequeño (característica de los animales Criollos). Sin embargo, su becerro presenta el fenotipo de la raza Holstein, evidenciando el cambio genético tipo absorbente en cuestión. Todos estos programas de cambio racial resultaron en la población de ganado lechero que tenemos hoy día.

\section{Problemas iniciales con las razas lecheras de clima templado y su adaptación en Puerto Rico}

$\mathrm{Al}$ ser introducidas al trópico, las razas europeas especializadas han confrontado una serie de retos que limitan su desempeño productivo en comparación con lo observado en los mismos animales bajo condiciones ideales en sus países de origen. En el caso de PR uno de estos factores limitantes lo ha sido la incidencia de enfermedades asociadas con la infestación con parásitos externos, como la garrapata (Cestero, 1947; Jones, 1951; Cortés et al., 2005); e internos, como la Fasciola hepatica (Frame et al., 1979), los cuales limitan considerablemente la producción del ganado lechero en nuestro país (Gaztambide, 1974; Cortés et al., 2010). De forma similar, la tuberculosis bovina fue una de las enfermedades que limitó grandemente la probabilidad de éxito de las primeras importaciones de animales lecheros mejorados a PR (Cestero, 1947). Además, existen considerables diferencias entre las dietas que reciben estos animales en los países de clima templado (i.e., el norte de EEUU) y la realidad nutricional de los trópicos (Cestero, 1947). El ensilaje de maíz y el heno de alfalfa son altamente utilizados en la industria lechera de EEUU, aportando un alto contenido de energía y proteína de calidad a la dieta de las vacas lactantes (Kezar, 2001; Knowlton y Nelson, 2003; Knowlton y Nelson, 2010). Desafortunadamente, los pastos tropicales maduran rápidamente, reduciendo así su potencial nutricional para producir leche (Yazman et al., 1979). En PR se ha tratado de compensar esta situación mediante el alto uso de alimento concentrado en la dieta de la vaca lechera (Ruiz y CancelMedina, 2006). Sin embargo, una alta inclusión de concentrado en la 
dieta bovina puede resultar en problemas de salud, incluyendo acidosis ruminal y laminitis (Salcedo et al., 2012). También, debido a que la salud, el consumo de alimento y la producción de leche de la vaca guardan una relación directamente proporcional (Leblanc, 2010), el manejo que estos animales reciben tiene un impacto directo sobre su desempeño productivo. Por ejemplo, prácticas de manejo inadecuadas pueden aumentar la incidencia de mastitis en el hato lechero (Rodrigues et al., 2005), potencialmente reduciendo así el volumen de leche producido (Lescourret y Coulon, 1994). Además de estos factores que limitan la producción de leche en PR, también se encuentran las condiciones climáticas tropicales, en las cuales se concentrará la discusión de esta parte del presente artículo.

Siendo originarias de países con condiciones ambientales templadas, las razas lecheras europeas introducidas a PR a partir de la primera década del siglo 20 han tenido gran dificultad para adaptarse a nuestro clima tropical (Gaztambide et al., 1952; Molina, 2001). Gaztambide et al. (1952) concluyeron que de todas estas razas introducidas a PR, la Holstein es la menos adaptable a las condiciones ambientales locales. Sin embargo, esta misma raza ha llegado a ser la más usada por nuestra industria lechera. Aunque los genes Criollos presentes en animales del primer cruzamiento antes mencionado (generación filial 1) aportan rusticidad para poder tolerar nuestras adversas condiciones climáticas (Gaztambide, 1974; Bracho et al., 2002), también suelen reducir el volumen de leche producido (Gaztambide, 1974; De Alba y Kennedy, 1985). Además, cuando la primera generación filial de estos cruces se vuelve a cruzar con alguna de las razas parentales, normalmente se pierde parte del vigor híbrido adquirido y si en generaciones siguientes se acerca a la raza mejorada pura, va mermándose la adaptabilidad al trópico. Esto ocurrió en PR luego de múltiples generaciones de cruzamientos absorbentes con las razas europeas, donde al acercarnos al fenotipo de estas, se perdió parte del vigor híbrido y resistencia al calor asociadas con el ganado Criollo (Cestero, 1947). Por ejemplo, si una vaca F1 raza europea x Criolla se cruza con un toro Criollo, en la progenie se reduce el volumen de leche producida (De Alba y Kennedy, 1985), pero se mejora su capacidad termorreguladora (MacPhail, 1963) y desempeño reproductivo (Zambrano et al., 2006). En el caso contrario, si esta vaca $\mathrm{F} 1$ es cruzada con un toro europeo, como ha ocurrido históricamente en PR, se aumenta el potencial genético para producir leche (De Alba y Kennedy, 1985), pero se sacrifica su capacidad para tolerar el clima tropical (MacPhail, 1963). Semejante relación inversa entre producción de leche y capacidad termorreguladora se observa en otros países donde han cruzado ganado nativo Bos indicus con razas Bos taurus europeas mejoradas (Tadesse y Dessie, 2003). 
Queda claro que a la hora de comparar valores de producción hay que tener en cuenta el impacto de las condiciones ambientales sobre la fisiología de la vaca. Dada la gran importación de semen y de animales a PR desde EEUU, podemos asumir que actualmente existe una gran similitud genética entre el ganado lechero de ambos países. Sin embargo, mientras la producción de leche diaria promedio en EEUU alcanzó cerca de unos 28 litros por vaca en ordeño entre los años 2013-2014 (USDA NASS, 2017); la cifra correspondiente en PR fue de solo 17.38 litros (ORIL, 2013-2014). Según Cestero (1947), para finales de la década del 1940 ya existían en PR vacas lecheras produciendo 17 litros de leche al día, aunque el promedio de producción era mucho menor (y había animales de tan baja producción como dos litros por día). Estos valores demuestran el impacto negativo que ejerce, al menos en parte, el estrés por calor sobre el desempeño de estos animales.

A pesar del reto que representan las condiciones tropicales, nuestro ganado lechero ha alcanzado un alto grado de adaptación. Según Bligh y Johnson (1973) el término "adaptación genotípica" hace referencia a una condición genéticamente fijada en una especie, la cual favorece su supervivencia en un ambiente particular. Ya una parte considerable del ganado mejorado y su progenie mediante cruzamientos absorbentes con nuestro ganado Criollo, ha vivido y se ha reproducido en PR por décadas. Al visitar vaquerías que importan ganado lechero de EEUU, tanto en el pasado (Gaztambide, 1974) como en la actualidad, es común observar los problemas que las novillas recién introducidas enfrentan para adaptarse en comparación con el ganado cuyas cepas llevan generaciones en la Isla. De hecho, algunos de esos animales recientemente importados, lejos de ser productivos, ni siquiera sobreviven en este nuevo ambiente si no se les provee cuidados especiales (Gaztambide, 1974). Por lo visto, aun con el pelaje característico de las razas de clima templado, los animales locales han logrado considerable adaptación a nuestro clima.

Las altas temperatura y humedad atmosféricas e intensiva radiación solar, que prevalecen en PR por un periodo considerable del día y de forma crónica durante el año, resultan en cierto grado de estrés térmico. Podemos visualizar este estrés sobre el animal como una balanza de dos platos, donde tenemos el calor disipado por la vaca al medio ambiente en uno de ellos y el calor producido metabólicamente y recibido del medio ambiente en el otro. Cuando la balanza se inclina hacia este segundo lado, la vaca se halla en una situación estresante. Ante esto la vaca responde aumentando su temperatura corporal y, subsecuentemente, reduciendo su consumo de alimento y producción de leche (Kadzere et al., 2002; West, 2003), así como su desempeño reproductivo (Jordan, 2003). Debido a que las razas especializadas introducidas 
a PR para mejorar nuestra producción de leche fueron originadas en países de clima templado, nuestras condiciones ambientales representan serios retos para su fisiología (Gaztambide et al., 1952). Cestero (1947) ya había señalado tempranamente este problema de adaptación a nuestro ambiente al introducir las razas europeas provenientes de EEUU. Sin embargo, nuestras vacas lecheras se han mostrado capaces de reproducirse y producir leche bajo las condiciones locales, aunque con menor eficiencia que lo típico de los EEUU, así que las mismas han logrado adaptarse relativamente bien al ambiente local.

\section{Vaca lechera pelona puertorriqueña}

Actualmente en PR los animales de las razas europeas mejoradas presentan diferentes tipos de pelo, incluyendo el pelaje largo y denso (característico del ganado desarrollado en países templados) y un pelaje sumamente corto y a veces brilloso (característico de los animales Criollos). A este segundo grupo se le conoce como animales "pelones". Estos presentan un pelaje sumamente corto en todo el cuerpo, tanto que son visibles las arrugas entre los ojos, a los lados de la cabeza y en el cuello, así como las venas a ambos lados del puente de la nariz, en las extremidades y en el tronco del cuerpo. Su borla (parte final del rabo) suele ser de menor tamaño que la observada en vacas de pelo normal, aunque existe variabilidad considerable entre individuos. Ejemplares de ambos tipos de pelo pueden observarse en varias razas en PR, incluyendo la Holstein (Figura 2; Sánchez et al., 2015; Sánchez-Rodríguez et al., 2016b) y la Jersey (Figura 3; Castro et al., 2015).

A principios de la década del 2000, el Dr. José Pantoja (Especialista en Ganado Lechero del Servico de Extención Agrícola, actualmente retirado) se dio a la tarea de identificar vacas lecheras pelonas alrededor de la Isla. De estos animales, los cuales eran principalmente descendientes de Holstein, un grupo de aproximadamente de 10 a 12 vacas fue llevado a Gurabo, algunos comprados y otros donados por diferentes ganaderos, donde pasaron a ser parte del hato de la Vaquería de la Estación Experimental Agrícola (EEA). Las operaciones de ordeño de dicho hato fueron descontinuadas el 5 de diciembre de 2007 y las vacas lactantes fueron transportadas inmediatamente a la vaquería de la EEA en Lajas. Durante los dos años siguientes (2008-2009), las vacas horras y las novillas también se transfirieron gradualmente de Gurabo a Lajas. Entre estos animales se encontraban las vacas pelonas y su descendencia inicial. El autor de este escrito fue testigo de este proceso ya que durante este tiempo trabajaba a jornal en la vaquería de la EEA en Lajas. También el Sr. Ricardo Montañez, quien trabajó con el hato lechero de la EEA en Gurabo y luego pasó a hacer lo mismo como empleado de la EEA en Lajas durante esta transición, tiene gran 


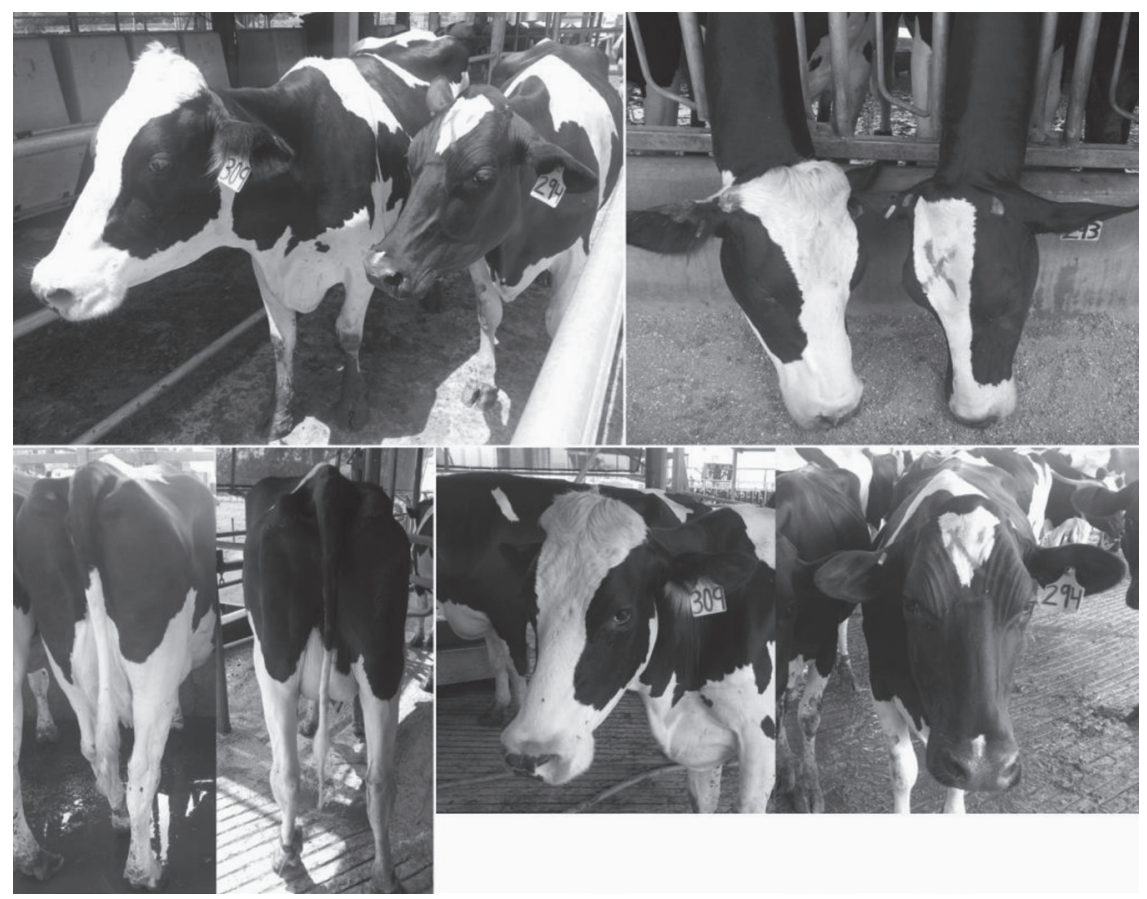

Figura 2. Vacas Holstein puertorriqueñas con pelaje normal (a la izquierda) y pelonas (a la derecha). En las pelonas el pelo es brilloso y tan corto que se observan sus arrugas y venas, el testuz parece haber sido recortado y la borla es de menor tamaño. Tomado de Sánchez et al., 2015.

familiaridad con estos eventos. Además de las vacas y novillas, varios toros Holstein pelones (incluyendo al "número uno"; hijo de la vaca pelona 495, una de las originalmente traídas a Gurabo), fueron seleccionados para reproductores y transferidos a Lajas donde se utilizaron como padrotes selectivamente por varios años. Luego de reubicadas en Lajas, estas vacas y su descendencia han continuado reproduciéndose, principalmente por inseminación artificial con semen de toros Holstein registrados disponibles comercialmente y transmitiendo esta deseada característica de pelo corto a una porción de las próximas generaciones. Otro hecho significativo ocurrido tarde en la primer década del 2000 fue la adquisición de un toro joven pelón Holstein, llamado Remanso Marie y registrado en la asociación de esta raza en EEUU, el cual fue donado a la vaquería de la EEA en Lajas por un ganadero del pueblo de Camuy. Este toro sirvió de padrote con una porción de las vacas del hato por varios años. Otros becerros pelones nacidos en el hato de la EEA en Lajas han sido seleccionados como reproductores durante este periodo, por lo que aportarán con su genética a las próximas ge- 


\section{Sánchez-Rodríguez/ Ganadería de Leche en Puerto Rico}
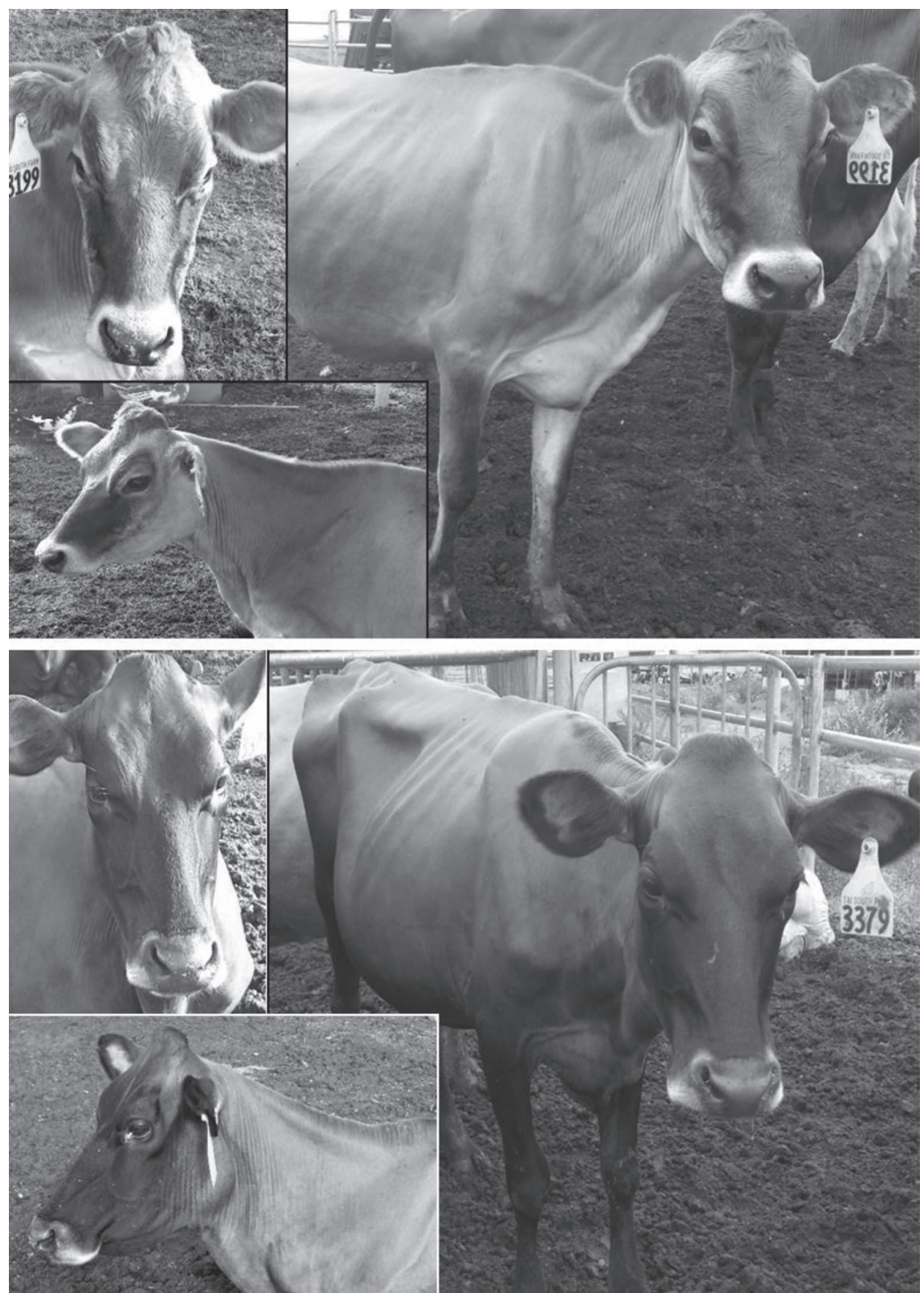

Figura 3. Ejemplos de una vaca Jersey puertorriqueña con pelaje normal (arriba) y de una pelona con alta influencia Jersey (abajo). En la pelona el pelo es brilloso y tan corto que se observan sus arrugas y venas y el testuz parece haber sido recortado. Modificado de Castro et al., 2015. 
neraciones. Por lo expuesto es muy probable que hoy día el grupo más numeroso de vacas Holstein pelonas puertorriqueñas se encuentre en la EEA de Lajas.

En los comienzos del interés científico en PR (además del Dr. José Pantoja) hacia estas vacas Holstein pelonas puertorriqueñas (alrededor de 2005-2010) era común escuchar el comentario asociando el desarrollo de estas a cruces entre el ganado Holstein y la raza Senepol. En un principio esta teoría parecía confiable debido a los siguientes dos puntos. El Senepol es una raza Bos taurus de color rojo altamente adaptada al trópico (Cianzio, 2002) y de pelo corto (Mariasegaram et al., 2007), lo cual se cree es una característica dominante (Olson et al., 2003). Además, la Universidad de la Florida consiguió animales de coloración blanca y negra de pelo corto mediante el cruce inicial de toros Senepol con vacas Holstein, seguido de un cruzamiento absorbente con toros Holstein (Dikmen et al., 2008; Dikmen et al., 2014). Sin embargo, el autor del presente manuscrito entiende pertinente aclarar lo siguiente. La raza Senepol fue introducida a nuestra Isla por primera vez en el año 1983 como resultado de gestiones hechas por el Dr. Danilo Cianzio del Departamento de Industria Pecuaria de la Universidad de Puerto Rico en Mayagüez (Cianzio, 2002). Asumiendo su cruzamiento con el ganado lechero de la Isla en ese momento, debemos tener en cuenta que el color negro de la raza Holstein es una característica dominante sobre el color rojo (Cole y Johansson, 1948; Klungland et al., 1995). Por esto, en los cruces de Senepol x Holstein blanco y negro, la progenie (generación filial primera) resulta ser de color negro en todo o en la mayor parte de su cuerpo (Isea-Villasmil y Villasmil-Ontiveros, 2002; Isea-Villasmil et al., 2003), a no ser que el parental Holstein aporte el gen rojo, en donde la progenie sería completa o casi completamente de este color (Sánchez, 2013). Lo mismo también ocurre en otros cruces que incluyen el ganado Holstein blanco y negro, por ejemplo Holstein $\mathrm{x}$ Jersey (Hooper, 1921; Guglielmone et al., 2002); Holstein x Angus Negro y Holstein x Angus Rojo (Cole y Johansson, 1948) y Holstein x Pardo Suizo (observación personal). Cuando esta generación filial primera es cruzada nuevamente con ganado Holstein, la próxima generación normalmente presenta manchas blancas de un mayor tamaño. Por lo general, toma al menos varias generaciones de cruzamientos absorbentes con la raza Holstein para obtener el patrón de color característico de esta raza, incluyendo sus características manchas blancas. Si se acepta como apropiado la práctica de inseminar la novilla por primera vez cuando esta alcanza el 65\% de su peso vivo adulto (Holstein Foundation, 1989) y si en nuestro caso dicho peso adulto es de $544 \mathrm{~kg}(1,200$ lb) en promedio, la primer inseminación se efectuaría a los $354 \mathrm{~kg}$ (780 lb) de peso. En un estudio realizado por nuestro grupo se observó que 
el ganado Holstein puertorriqueño de pelo normal de la vaquería de la EEA en Lajas alcanza este peso mínimo recomendado entre los 24 y 25 meses de edad (Muñiz-Cruz et al., 2017). Dado un largo periodo de gestación en el ganado lechero cercano a los nueve meses (Silva et al., 1992; Norman et al., 2009) y asumiendo que una novilla de la tercera generación filial del cruzamiento absorbente Senepol x Holstein presentaría un fenotipo similar al de una Holstein pura, tomaría sobre siete años conseguir un animal "Holstein pelón" mediante estos cruces. Sin embargo, en la Figura 4 se observan fotos de una novilla Holstein pelona tomada en San Germán en el año de 1986, es decir, solamente tres años después de la introducción del Senepol a PR. Por lo tanto, es imposible que en este corto periodo de tiempo esto pudiese llevarse a cabo, lo que prueba incorrecta esta teoría. Aunque sí es del conocimiento del autor la existencia en PR de animales pelones provenientes del cruce Senepol x Holstein en una limitada cantidad, estos fueron producidos en años recientes y el interés principal de este artículo es discutir sobre los animales descendientes de nuestro ganado Criollo. Aún más, en la página 43 de su libro, el Dr. Carlos Gaztambide Arrillaga mencionó la existencia en PR "dentro de la raza Holstein de un tipo de vaca de pelo corto, liso, fino, brillante y aceitoso que tiene bastante buena aclimatación a distintas condiciones tropicales" (Gaztambide, 1974). Esto ocurrió en el año 1974, es decir, nueve años antes de la introducción del Senepol a nuestra Isla.

Como se menciona anteriormente, el ganado Criollo de Hispanoamérica se caracteriza por un pelaje sumamente corto y en ocasiones brillante (Bethancourt y Toribio, 2013). Debido a que PR ya contaba con una población de vacas Criollas al momento de introducir las razas europeas modernas, en un programa de mejoramiento genético como el que se llevó a cabo en la Isla no es económicamente viable eliminar de inmediato a todos los animales Criollos y sustituirlos por otras razas. Cestero (1947) ya había señalado que el costo de tal práctica no sería factible para PR. Por lo tanto, se adoptó la estrategia de utilizar nuestra vaca Criolla como base para la introducción de genes de razas mejoradas a través de la inseminación artificial y monta natural hasta que la progenie resultante llegara a ser fenotípicamente muy similar a las razas importadas (Cestero, 1947). Si consideramos que la característica de pelo corto se hereda de forma dominante (Olson et al., 2003), sería de esperar que aún tras décadas de cruzamientos con toros de razas europeas mejoradas, este tipo de pelo corto habría de persistir en una parte considerable de la población de vacas de PR. Este, a entender del autor, es el caso de nuestro ganado pelón.

Por otro lado, una proporción de nuestras vacas pelonas es acorne (observación personal), lo cual nos presenta considerables ventajas. El 

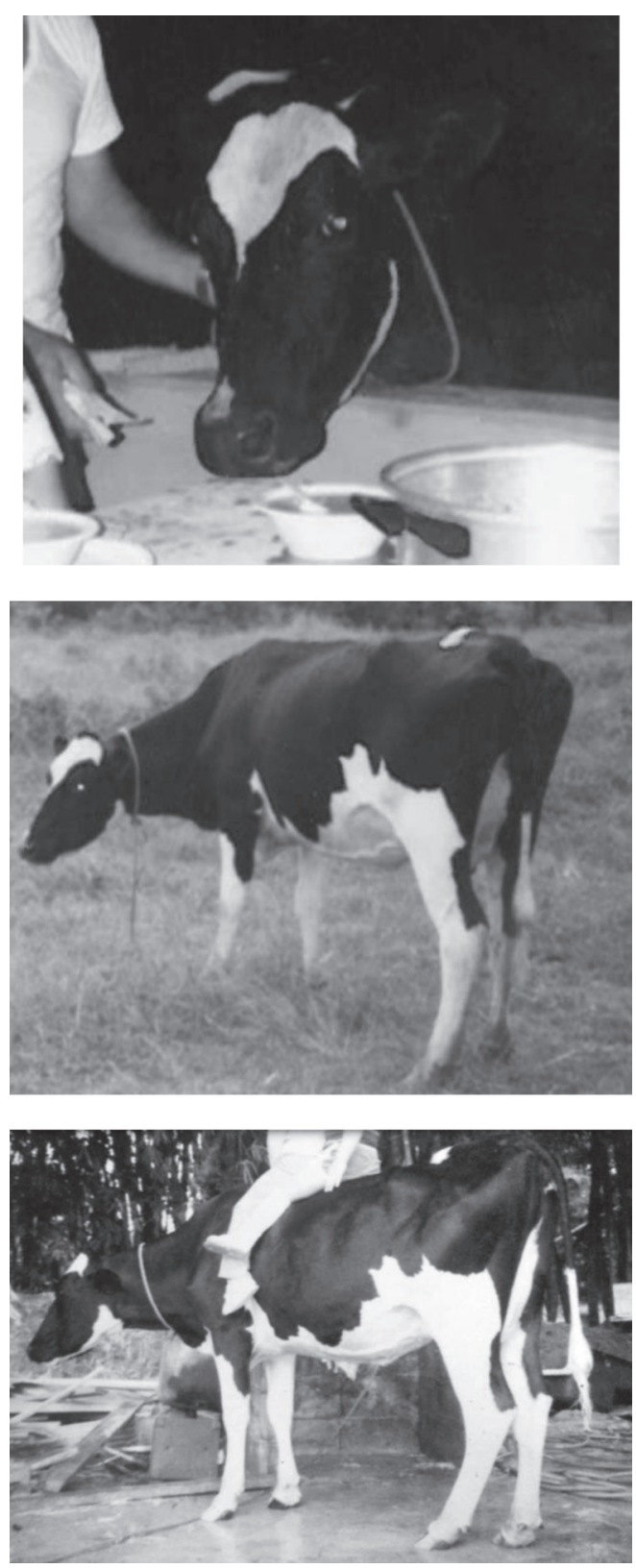

FiguRA 4. Imágenes de una novilla Holstein pelona propiedad del licenciado Luis Muñiz tomadas en el año 1986 en San Germán, PR. Note que la cara del animal no presenta remolinos de pelo, así como tampoco se observa que el pelo blanco se entremezcle con el negro en el borde de las manchas, como ocurre en el ganado de pelo normal. Tampoco hay pelos que sobresalgan en el resto del cuerpo. 
descornar es una práctica común en las vaquerías lecheras para minimizar el riesgo de heridas a otros animales o al personal de la finca causadas por animales con cuernos (Heinrich et al., 2009). Debido a que se trata de remover o dañar el tejido que da origen a los cuernos, esta práctica está asociada con considerable estrés por dolor al animal (Fraser, 2008; Heinrich et al., 2009), el cual podría reducir la ganancia de peso post-descuerne en bovinos jóvenes (Loxton et al., 1982; Goonewardene y Hand, 1991). Por esta razón, esta práctica es percibida negativamente por el público desde el punto de vista del bienestar animal (Vasseur et al., 2010), al punto de haber sido regulada por ley en diferentes partes de Europa (Veissier et al., 2008; Koknaroglu y Akunal, 2013). Tanta ha sido la presión del público que durante los últimos años ha aumentado considerablemente la disponibilidad de semen de toros lecheros acornes para inseminación artificial (Dechow, 2014). Se recomienda hacer selección genética hacia animales acornes (Koknaroglu y Akunal, 2013) debido a que, afortunadamente, el gen que codifica para esta característica en el ganado se hereda de forma dominante (Hoeschele, 1990). Siendo de importancia creciente esta característica, nuestro ganado pelón acorne puede representar una opción que maximice el desempeño animal, mientras a la vez se minimicen las percepciones negativas del público sobre la industria lechera y se reduzcan los gastos operacionales asociados con la práctica del descuerne.

Si la hipótesis del autor sobre la procedencia de nuestro ganado pelón es cierta y basado en que el ganado Criollo de Hispanoamérica es fenotípicamente muy similar debido a su origen común, se podría inferir que los demás países que fueron antiguas colonias de España en el Nuevo Mundo deben tener también en la actualidad ganado pelón con alta influencia de razas mejoradas como la Holstein. Sin embargo, es importante mencionar que las introducciones de ganado posteriores a la época de la colonización española pueden haber sido afectadas por los cambios políticos en cada uno de estos territorios. La historia política de PR y su relación con EEUU difiere considerablemente a la de los demás países, quienes en algún momento se independizaron y establecieron relaciones económicas con otras naciones. Por este hecho, aunque hoy día debe haber ganado con pelo corto en todas estas regiones, este puede presentar diferencias genómicas considerables entre un país y otro. De hecho, en algunos de estos otros países los cruces con ganado Bos indicus, el cual también tiene pelo corto, han sido altamente utilizados, inclusive en la actualidad. Por ejemplo, en el vecino país de la República Dominicana, dada la situación económica de su industria lechera, es común ver hatos de vacas lecheras predominantemente blancas y negras, pero con orejas colgantes y rabos largos y en compañía de un toro Bos indicus. Adicionalmente, en dicho país se desarrolló 
la raza Romana Roja del cruce de su ganado Criollo con ganado cebú de las razas Mysore y Nellore, para uso como animal de trabajo en la industria azucarera (Rouse, 1977; De Alba, 1987). Otro caso parecido es la Jamaican Hope, una raza que se desarrolló principalmente mediante el cruce de Jersey con Bos indicus en Jamaica (Wilson, 2009). Cuba por su parte desarrolló la raza Siboney (5/8 Holstein y 3/8 Cebú; Suárez et al., 2009). Por parte del ganado Bos taurus, en Venezuela existe la raza Carora, proveniente del cruce entre sus vacas Criollas y toros de la raza Pardo Suizo en las respectivas proporciones 3/8 : 5/8 (Rouse, 1977; Bracho et al., 2002). Estos son solo algunos ejemplos de razas desarrolladas en países americanos tropicales que pueden tener un pelaje corto, pero que genéticamente difieren de nuestra vaca pelona.

\section{Adaptación al trópico de la vaca lechera pelona}

Debido a características como el pelaje corto y su alta capacidad termorreguladora, la genética Bos indicus ha sido extensamente utilizada como una alternativa para aliviar el efecto negativo del estrés por calor en diversos países tropicales (Hansen et al., 2004). Sin embargo, estos animales también presentan desventajas importantes en comparación con las razas Bos taurus especializadas, incluyendo un menor desempeño productivo (Tadesse y Dessie, 2003), una menor terneza en su carne (Franke, 1980; Highfill et al., 2011), una pubertad más tardía y una gestación más larga (Randel, 2005), lo cual limita grandemente su utilidad en muchos sistemas de producción. Afortunadamente, la vaca Holstein pelona de PR tiene todas las características fenotípicas de esta raza, pero con un pelaje corto, lo cual plantea la interrogante de cuál es el desempeño de estos animales bajo nuestras condiciones ambientales. A continuación se presenta un compendio de los principales resultados de investigación que hemos obtenido como parte de un esfuerzo para caracterizar la capacidad termorreguladora y la productividad de los bovinos de pelo corto locales, especialmente el Holstein pelón.

Se ha obtenido evidencia de que, en efecto, las vacas Holstein pelonas puertorriqueñas presentan una menor temperatura corporal bajo condiciones ambientales cálidas que las de pelo normal, la cual es dependiente del grado de estrés por calor del animal (Sánchez et al., 2015; Sánchez-Rodríguez et al., 2016b). Esto quiere decir, que las diferencias en temperatura corporal entre animales pelones y sus contemporáneos de pelo normal aumentan a medida que la temperatura del aire se incrementa. En un estudio donde se compararon vacas pelonas de la raza Jersey con animales similares de pelo normal, aunque no se observaron diferencias en temperatura corporal durante la época fresca del año (diciembre), las primeras presentaron menores tasas de res- 
piración durante el día (Castro et al., 2015). Esta observación sugiere que el ganado de pelo normal tiene que hacer un esfuerzo respiratorio mayor para disipar el calor con miras a mantener con mínima alteración su temperatura corporal.

La capacidad para minimizar el aumento en temperatura corporal bajo condiciones calurosas debe ser de naturaleza multifactorial, por lo que también nos hemos dado a la tarea de investigar qué otros factores podrían incidir en esta marcada adaptación al trópico. Por ejemplo, estudios previos han concluido que un mayor hematocrito es una de las adaptaciones al calor presente en el ganado Criollo y en el Bos indicus en comparación con animales Bos taurus europeos (Gaztambide et al., 1952; Gaztambide, 1974; Turner, 1980). Sin embargo, los resultados de Contreras-Correa et al. (2016) sugieren que este no es el caso del ganado Holstein pelón puertorriqueño, debido a que no se encontraron tales diferencias entre animales de los dos tipos de pelo. Un mayor tamaño de las glándulas de sudor también ha sido asociado con una mayor capacidad de disipar calor corporal por evaporación en ganado Bos indicus (Hansen et al., 2004). Los resultados de Contreras-Correa et al. (2017) y Muñiz-Cruz et al. (2018) comprobaron que, en efecto, nuestro ganado Holstein pelón tiene glándulas de sudor de mayor tamaño en comparación con vacas contemporáneas de pelo normal. Estos hallazgos ayudan a explicar las razones para la superior capacidad termorreguladora en nuestro ganado lechero pelón. Además, es común observar al ganado pelón pastorear a pleno sol, mientras el ganado de pelo normal deja de pastorear, busca la sombra y se recuesta sobre el lodo (durante la época de lluvia).

Por otro lado, Muñiz-Cruz et al. (2017) evaluaron el crecimiento de novillas Holstein pelonas en comparación con animales similares de pelo normal desde los cuatro hasta los 34 meses de edad. Durante ese periodo, las novillas de pelo normal muestran un crecimiento lineal, mientras que en las pelonas se observa una curva cuadrática. Estos resultados sugieren posibles diferencias en la tasa de crecimiento y en la edad a la que se alcanza el peso vivo adulto en estos animales. De hecho, una investigación reciente de nuestro grupo (Soriano-Varela et al., 2018) encontró que las vacas adultas Holstein pelonas tienen cuerpos más cortos y profundos que las de pelo normal. Esta observación crea la interrogante de si existen diferencias en otras variables, como la edad a la cual se alcanza la pubertad o al primer parto, entre estos fenotipos.

Sin embargo, si los resultados de estas investigaciones no se traducen a un mayor desempeño productivo, el pelaje corto no tendría realmente una implicación económica en nuestra ganadería de leche. En este sentido, tanto los resultados de Delgado et al. (2014), como los de ContrerasCorrea et al. (2016) reportaron una mayor producción de leche diaria en 
vacas pelonas de las razas Jersey y Holstein que en sus contemporáneas de pelo normal. Por lo tanto, la discutida capacidad para minimizar el impacto negativo del ambiente en estos animales pelones puede resultar en ventajas productivas para beneficio de la ganadería tropical.

\section{Resultados con ganado pelón de otras razas}

En los últimos años también hemos tenido acceso a investigar otros animales Bos taurus pelones, incluyendo el ganado Senepol del hato en la Finca Montaña de la Estación Experimental Agrícola, Universidad de Puerto Rico, ubicado en Aguadilla, y las vacas Criollas lecheras de la República Dominicana mantenidas en el Centro de Investigación para el Mejoramiento de la Producción Animal (CIMPA, Santiago, República Dominicana). Sánchez-Rodríguez et al. (2016a) compararon la temperatura corporal entre novillas puras Senepol (con pelo rojo y corto), novillas cruzas Charbray x Senepol x Charolais (con pelo crema claro y corto) y novillas cruzas de la misma genética triracial (con pelo crema claro y largo) bajo las condiciones ambientales de PR. Se observó que un pelaje corto, independientemente del color, le permite al animal mantener una menor temperatura corporal durante las horas más estresantes del día. Por otro lado, García et al. (2015) evaluaron la capacidad termorreguladora de la vaca Criolla lechera de la República Dominicana, concluyendo que los valores ambientales establecidos en la literatura como causantes de estrés por calor en bovinos no ejercen un efecto negativo en estos animales. Es decir, que ante condiciones ambientales adversas para diferentes razas Bos taurus de clima templado seleccionadas como productoras leche o carne, estas vacas Criollas continúan siendo capaces de evitar un cambio en su fisiología, lo que sugiere una marcada adaptación al clima tropical. De hecho, similar a nuestro ganado Holstein pelón, es común observar a estas vacas pastando al sol durante las horas más calientes del día aún en verano. Wilson (2009) mencionó que entre las ventajas que poseen los animales Criollos sobre las razas especializadas de clima templado se encuentra una mayor capacidad de consumir alimentos de baja calidad y utilizar los mismos con relativa eficiencia. La observación casual sugiere que el ganado Criollo de PR y el de la República Dominicana son capaces de mantener una buena condición corporal aun cuando consumen solamente gramíneas tropicales de limitado valor nutricional. Este posible atributo de estas razas de pelo corto requiere investigación para su evaluación científica.

\section{CONCLUSIÓN}

El ganado traído por los colonizadores españoles al Nuevo Mundo hace varios siglos sentó los inicios de la ganadería actual en nuestro 
país. A través de un extenso proceso, mayormente de selección natural, de estos primeros animales se desarrolló el ganado Criollo de Hispanoamérica tropical, animales bien adaptados a condiciones ambientales calurosas y húmedas. Si bien hubo importación directa a PR de ganado de razas templadas seleccionadas para leche, fueron las vacas Criollas las que sirvieron de base en un amplio programa de mejoramiento genético mediante cruzamientos absorbentes con razas europeas especializadas. Tras varias décadas de este proceder se ha desarrollado una población de animales con todas las características fenotípicas de varias razas europeas, pero aun así algunos individuos presentan el pelo corto característico del ganado Criollo. Estudios en años recientes indican que esta característica, al igual que otros rasgos como un mayor tamaño de sus glándulas sudoríparas, hacen que estos animales pelones sean mejor adaptados a producir bajo nuestras condiciones ambientales. En vista de los efectos negativos que se le atribuyen al calentamiento global sobre la agricultura mundial futura, este fenotipo de pelo corto debe ser considerado como una opción para ayudar a mantener un abasto de comida adecuado en las regiones cálidas del mundo.

\section{LITERATURA CITADA}

Baldrich, J.J., 1999. Jack Delano, ¿un expatriado al servicio del Estado? Revista Mexicana del Caribe 4(7): 36-62.

Barrera, G.P., R. Martínez, J.E. Pérez, N. Polanco y F. Ariza, 2006. Evaluación de la variabilidad genética en ganado Criollo Colombiano mediante 12 marcadores microsatélites. Anim. Genet. Resour. Inform. 38: 35-45.

Bethancourt, H. y B. Toribio, 2013. Caracterización genética del ganado Criollo Lechero Dominicano utilizando microsatélites. Revista Agropecuaria y Forestal APF. 2(1): 43-48.

Bracho, I., G. Contreras, M. Pirela y S. Zambrano, 2002. La raza Criollo Limonero: Una realidad para la ganadería de doble propósito. Avances en la Ganadería de Doble Propósito. Pp.10-25.

Brau, S., 2011. La colonización de Puerto Rico: desde el descubrimiento de la isla hasta la reversión a la corona española de los privilegios de Colón. Instituto de Cultura Puertorriqueña.

Canales, A.M., 2014. Caracterización genética y morfológica de vacas de la raza criollo lechero tropical. Tesis de Maestría. Universidad Veracruzana. Facultad de Medicina Veterinaria y Zootecnia.

Castro, A., G. Muñiz, J. Curbelo, M. Pagán, A. Mesonero, A. de Jesús, N. Lluch y H. Sánchez, 2015. Effect of the environmental conditions over the vaginal temperature and respiration rate on wild type and slick- haired Puerto Rican Jersey cows. Joint Annual Meeting ADSA-ASAS 2015. July 12-16- Orlando Florida.

Cestero, H.R., 1947. Crossbreeding as a means to improve dairy cattle in Puerto Rico. Thesis for the Master of Science. Department of Dairy Husbandry. Kansas State College of Agriculture and Applied Science.

Cianzio, D., 2002. Historia breve del ganado Senepol en Puerto Rico: Un informe en colaboración. Simposio Senepol, Santa Cruz, USVI 8-10 de noviembre de 2002. 1-7 pp.

Cole, L.J. y I. Johansson, 1948. Inheritance in crosses of Jersey and Holstein-Friesian with Aberdeenangus cattle. II. Color and white spotting. The American Naturalist. 82(805):202-233. 
Contreras-Correa, Z., G. Muñiz-Colón, M. Pagán-Morales, A. Mesonero-Morales, J. Curbelo-Rodríguez y H.L. Sánchez-Rodríguez, 2016. Hematocrit, milk yield, and production related parameters comparisons between slick and wildtype-haired Puerto Rican Holstein cows. Joint Annual Meeting, ASAS-ADSA-CSAS-WSASAS. Salt Lake City, Utah. July 19-23, 2016.

Contreras-Correa, Z.E., N. Peña-Alvarado, W. Torres-Ruiz, J. R. Almodóvar-Rivera, K. I. Domenech-Pérez, C. Youngblood, M. Pagán-Morales, A. Mesonero-Morales, J. Curbelo-Rodríguez, P. F. Randel-Follin, G. C. Muñiz-Colón, V. Colón-González, Á. L. Jiménez-Arroyo, G. M. Jiménez-Arroyo y H. L. Sánchez-Rodríguez, 2017. Slickhaired Puerto Rican Holstein cows have larger sweat glands than their wild typehaired counterparts. ADSA 2017. June 25-28- Pittsburgh, Pennsylvania.

Contreras, G., Z. Chirinos, E. Molero y A. Paéz, 2012. Medidas corporales e índices zoométricos de toros Criollo Limonero de Venezuela. Zootecnia Tropical, 30(2):175-181.

Cortés, M., A. Pantoja, W. Robles y J. Pantoja, 2005. Tick incidence in Puerto Rico. J. Agric. Univ. P.R. 89(1-2): 59-66.

Cortés, M., B. Vallejo, L. Gayol, y R. Montañez, 2010. Datos socioeconómicos, prácticas de manejo y frecuencia de enfermedades o condiciones de salud en las vaquerías de Puerto Rico. J. Agric. Univ. PR. 94(3-4): 255-268.

Cosme, F., 2009. Reforma agraria en Puerto Rico, 1757-1800: demolición de hatos y tierras para la agricultura. Universidad de Puerto Rico-Río Piedras.

De Alba, J., 1987. Criollo cattle of Latin America. FAO Animal Production and Health Paper (FAO).

De Alba, J. y B. Kennedy, 1985. Milk production in the Latin-American Milking Criollo and its crosses with the Jersey. Anim. Sci. 41(2): 143-150.

Dechow, C., 2014. Artificial breeding. Polled genetics are gaining momentum. Hoard's Dairyman. Julio 2014. 458 pp.

Delano, J., 1990. Puerto Rico Mio: four decades of change; photographs. Smithsonian Institute Press.

Delgado, R., G. Colón, Z. Crespo, V. Colón, P. Cordero, G. Vargas, E. Lozada, E. Arcelay, C. Cabrera, E. Riquelme, G. Muñiz, A. de Jesus, N. Lluch y H. Sánchez, 2014. Asociación entre raza, tipo de pelo y producción de leche en vacas lecheras en Puerto Rico. Reunión Científica de la Sociedad para las Ciencias Agrícolas. Rincón of the Seas. Rincón, PR.

Departamento de Agricultura de Puerto Rico, (sa). Reglamento número 4442. Reglamento para regir el programa de incentivos para la importación de vacas lecheras. Aprobado el 3 de mayo de 1991. Estado Libre Asociado de Puerto Rico, Departamento de Agricultura, Administración de Fomento Agrícola.

Díaz-Alfaro, A., 2011. Terrazo: El Josco (9na Edición). Editorial Plaza Mayor.

Dikmen, S., E. Alava, E. Pontes, J.M. Fear, B.Y. Dikmen, T.A. Olson y P.J. Hansen, 2008. Differences in thermoregulatory ability between slick-haired and wild-type lactating Holstein cows in response to acute heat stress. J. Dairy Sci. 91(9): 3395-3402.

Dikmen, S., F.A. Khan, H.J. Huson, T.S. Sonstegard, J.I. Moss, G.E. Dahl y P.J. Hansen, 2014. The SLICK hair locus derived from Senepol cattle confers thermotolerance to intensively managed lactating Holstein cows. J. Dairy Sci. 97(9): 5508-5520.

Frame, A. D., P. Bendezú, H. Mercado, H. Otiniano, S.J. Frame y W Flores, 1979. Increase of Bovine Fascioliasis in Puerto Rico as Determined by Slaughterhouse Surveys. J. Agric. Univ. P.R. 63(1): 27-30.

Franke, D.E., 1980. Breed and heterosis effects of American zebu cattle. J. Anim. Sci. 50: $1206-1214$.

Fraser, D., 2008. Understanding animal welfare. Acta Veterinaria Scandinavica 50(1): 1-7.

García, J., C. Santana, C. Cabrera, M. Pagán y H. Sánchez, 2015. Evaluación de la capacidad termorreguladora de la vaca Criolla Lechera de la República Dominicana. Tesis de Maestría. Universidad de Puerto Rico, Recinto de Mayagüez. Departamento de Ciencia Animal.

Gaztambide, C., 1974. Ganado vacuno: Su aclimatación, cuido y manejo en los trópicos. Talleres de Artes Gráficas. Departamento de Instrucción Pública. San Juan, PR. 
Gaztambide, C., W.L. Henning y R.C. Miller, 1952. The effects of environmental temperature and relative humidity on the acclimation of cattle to the tropics. J. Anim. Sci. 11: 50-60.

Gaztambide, F. y P. Arán, 1941. La Isla de Puerto Rico. Rand McNally y Compañía.

Goonewardene, L.A. y R.K. Hand, 1991. Studies on dehorning steers in Alberta feedlots. Can. J. Anim. Sci. 71(4): 1241-1247.

Guglielmone, A.A., M.M. Volpogni, H. Castro, A.J. Mangold y O.S. Anziani, 2002. A study of relative horn fly, Haematobia irritans (Diptera: Muscidae), abundance on Holstein steers and steers of two Holstein crosses. Vet. Parasitol. 109(1): 141-145.

Hansen, P. J., 2004. Physiological and cellular adaptations of zebu cattle to thermal stress. Anim. Reprod. Sci. 83: 349-360.

Heinrich, A., T.F. Duffield, K.D. Lissemore, E.J. Squires y S.T. Millman, 2009. The impact of meloxicam on postsurgical stress associated with cautery dehorning. $J$. Dairy Sci. 92(2):540-547.

Highfill, C.M., O.E. Font, M.E. Dikeman y D. Kropf, 2011. Tenderness and intramuscular lipid of most major muscles from Bos indicus cattle are less than Bos taurus cattle. Kansas Agric. Expt. Station, Research Reports.

Hoeschele, I., 1990. Potential gain from insertion of major genes into dairy cattle. $J$. Dairy Sci. 73(9): 2601-2618.

Holstein Foundation Inc., 1989. Dairy Cattle Reproduction. http://www.holsteinfoundation.org/pdf_doc/workbooks/Dairy_Cattle_Reproduction.pdf Revisado el 19 de mayo de 2017.

Hooper, J.J., 1921. Color of cross bred calves. J. Hered. 12(10): 480.

Huson, H. J., E.S. Kim, R.W. Godfrey, T.A. Olson, M.C. McClure, C.C. Chase, R. Rizzi, A.M.P. O’Brien, C.P. Van Tassell, J.F. García y T.S. Sonstegard, 2014. Genome-wide association study and ancestral origins of the slick-hair coat in tropically adapted cattle. Front. Genet. 5:101: 1-12.

Isea Villasmil, W., R. Román Bravo, Y. Villasmil Ontiveros y J.A. Aranguren Méndez, 2003. Crecimiento de terneros cruzados Senepol en el estado Zulia, Venezuela. Revista Científica. 13(2): 130-138.

Isea-Villasmil, W. y J.A. Aranguren-Méndez, 2005. Clasificación fenotípica en vacas mestizas. Manual de Ganadería de Doble Propósito. Ediciones Astro Data, SA Maracaibo, Venezuela, 75-81.

Isea-Villasmil, W. y Y. Villasmil-Ontiveros, 2002. Peso al nacimiento de terneros cruzados Senepol en el Estado Zulia, Venezuela. Revista Científica 12(2): 121-126.

Jones, E.M., 1951. Effect of breeding policy on milk production in the West Indies. Imperial College of Tropical Agriculture. 1-21.

Jones, C.M., 2006. One hundred years of inquiry and innovation: An illustrated history of the American Dairy Science Association. Long Prairie, MN: Banta Publications.

Jordan, E.R., 2003. Effects of heat stress on reproduction. J. Dairy Sci. 86:(E. Suppl.):E104-E114.

Kabumbuli, R., y J. Phelan, 2003. Heifer-in-trust schemes: the Uganda experience. Dev. Pract. 103-110.

Kadzere, C.T., M.R. Murphy, N. Silanikove y E. Maltz. 2002. Heat stress in lactating dairy cows: A review. Livest. Prod. Sci. 77(1): 59-91.

Kezar, W.W., 2001. Successful use of high quality corn silage for dairies in the western United States. Proceedings, 31st California Alfalfa and forage Symposium (pp. 1213).

Klungland, H., D.I. Vage, L. Gomez-Raya, S. Adalsteinsson y S. Lien, 1995. The role of melanocyte-stimulating hormone (MSH) receptor in bovine coat color Determination. Mamm. Genome 6(9): 636-639.

Knowlton, K. F. y J.M. Nelson, 2010. World of dairy cattle nutrition. Brattleboro, Vermont. Holstein Foundation. http://www.holsteinfoundation.org/pdf_doc/workbooks/ DairyCattleNutrition.pdf

Knowlton, K. F. y J.M. Nelson, 2003. World of dairy cattle nutrition. Brattleboro, Vermont. Holstein Foundation. https://www.nebraskamilk.org/wp-content/uploads/sites/2/2014/12/Dairy-Cattle-Nutrition.pdf 
Koknaroglu, H. y T. Akunal, 2013. Animal welfare: An animal science approach. Meat Sci. 95(4): 821-827.

LeBlanc, S., 2010. Monitoring metabolic health of dairy cattle in the transition period. $J$. Reprod. Dev. 56(S), S29-S35.

Lescourret, F. y J.B. Coulon, 1994. Modeling the impact of mastitis on milk production by dairy cows. J. Dairy Sci. 77(8): 2289-2301.

Loxton, I.D.L., M.A. Toleman y A.E. Holmes, 1982. The effect of dehorning Brahman crossbred animals of four age groups on subsequent bodyweight gain. Aust. Vet. J. 58(5): 191-193.

MacPhail, D.D., 1963. Puerto Rican dairying: A revolution in tropical agriculture. Geogr. Rev. 53(2): 224-246.

Mariasegaram, M., C.C. Chase, J.X. Chaparro, T.A. Olson, R.A. Brenneman y R.P. Niedz, 2007. The slick hair coat locus maps to chromosome 20 in Senepol derived cattle. Anim. Genet. 38(1): 54-59.

Martínez, A.M., L.T. Gama, J. Cañón, C. Ginja, J.V. Delgado, S. Dunner, V. Landi, I. Martín-Burriel, M.C.T. Penedo, C. Rodellar, J.L. Vega-Pla, A. Acosta, L.S. Álvarez, E. Camacho, O. Cortés, J.R. Marques, R. Martínez, R.D. Martínez, L. Melucci, G. Martínez-Velázquez, J.E. Muñoz, A. Postiglioni, J. Quiroz, P. Sponenberg, O. Uffo, A. Villalobos, D. Zambrano y P. Zaragosa, 2012. Genetic footprints of Iberian cattle in America 500 years after the arrival of Columbus. PLoS One. 7(11), e49066: 1-13.

McTavish, E.J., J.E. Decker, R.D. Schnabel, J.F. Taylor y D.M. Hillis, 2013. New World cattle show ancestry from multiple independent domestication events. Proc. Natl. Acad. Sci. 110(15):E1398-E1406.

Molina, J., 2001. La Industria Lechera en Puerto Rico. Nupress of Miami, Inc.

Muñiz Cruz, J.M., G.C. Muñiz Colón, P.F. Randel Folling, C.J. Cabrera Cabrera, C. Youngblood, K.I. Domenech Pérez y H.L. Sánchez Rodríguez, 2017. Monthly body weight change in wild type and slick haired post-weaned Puerto Rican Holstein heifers. ADSA 2017. June 25-28- Pittsburgh, Pennsylvania.

Muñiz-Cruz, J.M., N. Peña-Alvarado, W. Torres-Ruiz, J.R. Almodóvar-Rivera, K.I. Domenech-Pérez, Z.E. Contreras-Correa, G.C. Muñiz-Colón, A.C. Cortés-Arocho, J.M. Santiago-Rodríguez, S. Ruiz-Ríos, G.A. Soriano-Varela, N.N. Cortés-Viruet, A.L. Jiménez-Arroyo, G.M. Jiménez-Arroyo y H.L. Sánchez-Rodríguez, 2018. Sweat gland cross-sectional cut areas comparisons between slick and wild typehaired Holstein and Senepol cows in Puerto Rico. ADSA 2018. June 24-27- Knoxville, Tennessee.

Norman, H.D., J.R. Wright, M.T. Kuhn, S.M. Hubbard, J.B. Cole y P.M. VanRaden, 2009. Genetic and environmental factors that affect gestation length in dairy cattle. $J$. Dairy Sci. 92(5): 2259-2269.

Normas para Regir el Programa de Inseminación Artificial. Estado Libre Asociado de Puerto Rico. Departamento de Agricultura. Administración de Fomento y Desarrollo Agrícola. Aprobado el 29 de octubre de 1980.

Olson, T.A., C. Lucena, C.C. Chase y A.C. Hammond, 2003. Evidence of a major gene influencing hair length and heat tolerance in cattle. J. Anim. Sci. 81(1): 80-90.

ORIL (Oficina de la Reglamentación de la Industria Lechera). Estado Libre Asociado de Puerto Rico. Departamento de Agricultura. Informe anual para el año fiscal 20132014.

Ortiz, M. B., 1997. Las razas autóctonas españolas y su participación en los bovinos criollos iberoamericanos. Simposio sobre utilización de razas y tipos bovinos creados y desarrollados en Latino América y el Caribe. APLA, XV Reunión. Maracaibo, Venezuela, 24-28.

Picó, F., 2008. Historia general de Puerto Rico. Ediciones Huracán.

Primo, A. T., 1992. El ganado bovino ibérico en las Américas: 500 años después. Archivos de Zootecnia 41(154): 421-432.

Pyle, S., A. Celestine, A. Ging y B. Christy, 2016. Puerto Rico: A sociological analysis of disparities in hispanic identification. Florida State University Libraries.

Ramírez, A., 2007. Contribución del Servicio de Extensión Agrícola de la Universidad de Puerto Rico al progreso y desarrollo de la industria lechera. Reunión de la Asocia- 
ción Latinoamericana de Producción Animal. 21 al 25 de octubre de 2007. Cusco, Perú.

Randel, R. D., 2005. Reproduction of Bos indicus breeds and crosses. Proceedings Applied Reproductive Strategies in Beef Cattle. November 12 and 13, 2005, Texas A\&M University, College Station.

Rodero, A., J.V. Delgado y E. Rodero, 1992. El ganado andaluz primitivo y sus implicaciones en el descubrimiento de América. Archivos de Zootecnia 41(154): 383-400.

Rodrigues, A.C.O., D.Z. Caraviello y P.L. Ruegg, 2005. Management of Wisconsin dairy herds enrolled in milk quality teams. J. Dairy Sci. 88(7): 2660-2671.

Rouse, J. E., 1977. The Criollo: Spanish cattle in the Americas. University of Oklahoma Press.

Ruiz, T. M. y E. Cancel-Medina, 2006. Performance of Holstein cows fed two levels of concentrate supplementation and ruminally undegraded protein. J. Agric. Univ. P.R. 90(1-2): 9-26.

Salcedo, G., Y. Tatiana, R. Junior, C. Stefenson, T. Gómez, D. Juliana, R. Calderón, L. Gabriel, M. Machado y A. M. Ardila, 2012. Acidosis ruminal en bovinos lecheros: implicaciones sobre la producción y la salud animal-Ruminal. REDVET. 13(4):1-11.

Sánchez, H., A. Castro, M. Pagán, J. Curbelo, A. Mesonero y G. Muñiz, 2015. Effects of the thermal humidity index on vaginal temperature of slick- and wild type- haired Puerto Rican Holstein cows. Joint Annual Meeting ADSA-ASAS 2015. Orlando, Florida. julio 12-16, 2015.

Sánchez, J.M., 2013. El Senepol en la producción de leche en el trópico seco. Proyecto Las Cantaritas. Bajura de Guanacaste, Costa Rica.

Sánchez-Rodríguez, H., K. Domenech, G. Rivera, A. Casas y G. Muñiz, 2016a. Diurnal vaginal temperature cycles of Senepol and crossbred beef heifers with different hair coat types and colors under tropical conditions. J. Agric. Univ. P.R. 100(1): 13-26.

Sánchez-Rodríguez, H.L., Z. Contreras Correa, M. Pagán Morales, J. Curbelo Rodríguez, A. Mesonero Morales, C. Cabrera Cabrera y G. Muñiz Colón, 2016b. Associations between the environmental conditions and vaginal temperature in wild-type and slick-haired Puerto Rican Holstein cows. Joint Annual Meeting, ASAS-ADSACSAS-WSASAS. Salt Lake City, Utah. julio 19-23, 2016.

Scarano, F.A., 2008. Puerto Rico: Cinco siglos de historia. McGraw-Hill.

Silva, H.M., C.J. Wilcox, W.W. Thatcher, R.B. Becker y D. Morse, 1992. Factors affecting days open, gestation length, and calving interval in Florida dairy cattle1. J. Dairy Sci. 75(1): 288-293.

Soriano-Varela, G., M. Mercado-Ayala, E. Matos-Padilla, G. Muñi-Colón y H.L. SánchezRodríguez, 2018. Body measurements comparison between slick and wild typehaired Puerto Rican Holstein cows. ADSA 2018. June 24-27- Knoxville, Tennessee.

Sponenberg, D.P. y T.A. Olson, 1992. Colonial Spanish cattle in the USA: History and present status. Archivos Zootecnia. 41: 401-414.

Suárez, M.A., I. Zubizarreta y T. Pérez, 2009. Genotype by environment interaction in "Siboney de Cuba" cattle. Livestock Res. Rural Dev. 21(9).

Tadesse, M. y T. Dessie, 2003. Milk production performance of Zebu, Holstein Friesian and their crosses in Ethiopia. Livestock Res. Rural Dev. (15)26.

The Seagoing Cowboys. https://seagoingcowboysblog.wordpress.com/tag/puerto-rico/. Revisada el 19 de mayo de 2017.

Turner, J.W., 1980. Genetic and biological aspects of Zebu adaptability. J. Anim. Sci. 50 (6): 1201-1205.

United States Department of Agriculture. National Agricultural Statistics Service. Milk: Production per cow by year, US. https://www.nass.usda.gov/Charts_and_ Maps/Milk_Production_and_Milk_Cows/cowrates.php https://www.nass.usda.gov/ Charts_and_Maps/Milk_Production_and_Milk_Cows/cowrates.php. Revisado el 15 de mayo de 2017. Revisado el 20 de mayo de 2017.

Vasseur, E., F. Borderas, R.I. Cue, D. Lefebvre, D. Pellerin, J. Rushen, K.M. Wade y A.M. De Passillé, 2010. A survey of dairy calf management practices in Canada that affect animal welfare. J. Dairy Sci. 93(3): 1307-1316. 
Veissier, I., A. Butterworth, B. Bock y E. Roe, 2008. European approaches to ensure good animal welfare. Appl. Anim. Behav. Sci. 113(4): 279-297.

West, J.W., 2003. Effects of heat-stress on production in dairy cattle. J. Dairy Sci. 86: 2131-2144.

Wilson, R. T., 2009. Fit for purpose-the right animal in the right place. Trop. Anim. Health Prod. 41(7): 1081-1090.

Yazman, J. A., R. E. McDowell, H. Cestero, F. Román-García y J.A. Arroyo-Aguilú, 1979. Supplementation of dairy cows grazing intensively managed tropical grass pastures at two stocking rates. J. Agric. Univ. P.R. 63(3): 281-293.

Zambrano, S., G. Contreras, M. Pirela, H. Cañas, T. Olson y A. Landaeta-Hernández, 2006. Milk yield and reproductive performance of crossbred Holstein $\times$ Criollo Limonero cows. Revista Científica 16(2): 155-164. 